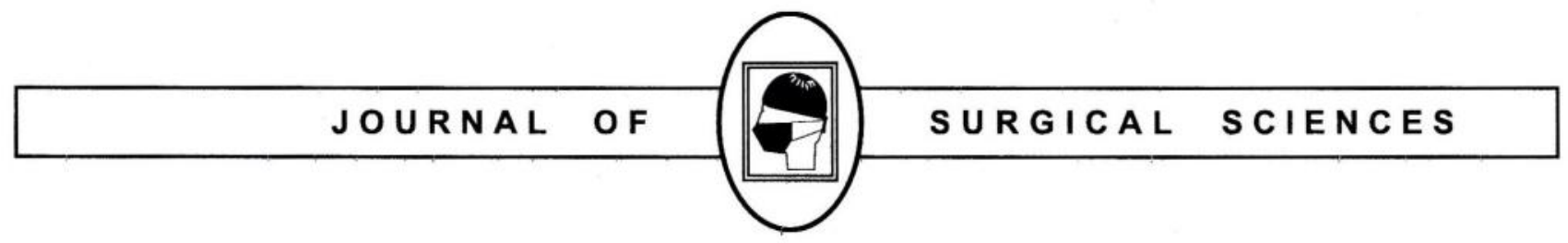

\title{
Editorial
}

\section{THE PRACTICES OF DISCLOSURE AND MANAGEMENT OF MEDICAL ERRORS BY SURGICAL TRAINEES-BETTER PREPARING A FUTURE SURGEON}

\author{
Md. Zulfiqur Rahman Khan', Md. Ibrahim Siddique ${ }^{2}$ \\ ${ }^{1}$ Professor of Hepatobiliary and Pancreatic Surgery, ${ }^{2}$ Professor of General Surgery, Department of Surgery, \\ Bangabandhu Sheikh Mujib Medical University, Shahbagh, Dhaka.
}

Human error is unavoidable in healthcare and some error is inevitable in any healthcare process ${ }^{1}$. Human error is the major causal factor of industrial and transportation accidents and healthcare is not immune to the effects of human error ${ }^{2}$. Human performance principle tell us that humans are fallible and that errors can occur through doing the wrong thing- errors of commission; failure to act- errors of omission; or errors of execution- doing the right thing incorrectly ${ }^{3}$. Common medical errors include adverse drug events, improper transfusions, surgical injuries, wrong-site surgery and mistaken identify patients. Most serious errors are likely to occur in the emergency department, operating rooms and intensive care unit ${ }^{4}$. Improvements in patient safety result primarily from organizational and individual learning, particularly with reference to trainee doctors ${ }^{5}$.

Junior Doctors are an important population who are more vulnerable to medical error and represent an enhanced level of risk to patient safety ${ }^{5,6}$. An argument exists for teaching medical students about the positive value of medical error, calling for a move from the current culture of 'name, blame and shame' towards, a 'no blame' scenario where errors can be more openly admitted and discussed 7,8 . Morbidity and mortality conferences arose from the need to pool experiences and developed as a forum for physicians to discuss unexpected complications of patient care and medical error ${ }^{9}$. The first victim of an adverse event is the patient and their family. Doctors do not purposely set out to injure patients but when it does happen due to an error they may experience a range of emotions including distress, shame, guilt, fear and depression. To that extent they can be regarded as a 'second victim'. Indeed, these second victims suffer from profound physical and psychological disturbances leading to further deficits in patient care. In order to decrease errors and increase patient safety many medical team training programmes have now been developed internationally, often based on crew resource management (CRM) programmes, the team training strategy used in the aviation industry ${ }^{3}$.

This kind of training heightens safety awareness, improves communication and decision making behaviors and has been shown to reduce errors and surgical mortality. In a qualitative study of junior doctor's accounts of error, kroll et al. found that errors were common and sometimes serious in a group of 38 pre-registration house officers. kroll explored their response to error and highlighted that there was a norm of selective disclosure. Fear and short tenure were cited as reasons to impede disclosure ${ }^{10}$. As the advancement of surgical career depends on favorable reports from supervisors regarding competence, performance and professional development, often reporting and acknowledgement of error can be thought to be detrimental to career progression ${ }^{11}$. Within a team environment, the level and availability of support appeared to affect junior doctor's willingness to seek help or disclose error: feeling of resentment, competition, being bullied or scape-goated were all described as influences on interaction with colleagues. Trainees can miss the 'learning moment' if there is inadequate senior input or trainees themselves do not 
disclose error. Kroll highlighted that most learning occurred when a situation was discussed and feedback was constructed and supportive ${ }^{10}$. Disclosure of medical errors needs to be viewed as a process and there is a need for a comprehensive educational programme. Medical education needs to be restructured to ensure human factor and patient safety education becomes introduced at an early level of training and to ensure these skills are developed through continuous training ${ }^{12}$.

Human error is unavoidable. Unfortunately, blame is still a mainstay solution to medical error and adverse events. Individuals learn from mistakes and thus disclosure of error is important in patient safety. Junior doctors are a unique population, with a higher propensity to medical error. The 'name, blame and shame' culture must be replaced with a culture, which is open, transparent, supportive and committed to learning ${ }^{13}$. Resident training programmes must ensure development of constructive coping skills by facilitating candid discussion and learning subsequent to medical error events. Motivated and well-prepared healthcare workers who are educated and trained to work together can reduce risks to patients, themselves and their colleagues, especially if they manage incidents positively and make the most of opportunities to learn from adverse events and near misses. Healthcare institutions need to provide this kind of educational support for their future workforce.

\section{References:}

1. Institute of Medicine. Committee on Quality of Health Care in America. Crossing the Quality Chasm: A New Health System for the 21st century. Washington, DC. National Academy Press;2001

2. O'Connor P, Keogh IJ. Addressing human error within the Irish healthcare system. Ir Med J 2011; 104(1): 5-6

3. Williams NS, Bulstrode CJK, O'Connel PR (editors). Bailey \& Love's Short Practice of
Surgery. 26th ed. Taylor \& Francis Group. LLC : New York $2013 ; 161-8$

4. Kohn LT, Corrigan JM, Donaldson MS. To err is human: building a safer health system. Washington DC : Institute of Medicine ; 2000

5. Firth-Cozens J. Cultures for improving patient safety through learning: the role of teamwork. Qual Health Care 2001; $10: 26-31$

6. Health Do. Safe foundations: junior doctors and patient safety. Department of Health;2008

7. Lester $\mathrm{H}$, Tritter JQ. Medical error: a discussion of the medical constructions of error and suggestions for reforms of medical education to decrease error. Med Educ 2001; 35: 855-61

8. Cole A. Should complaints be treasured? Health Serv J 1995; $310: 24-7$

9. Mc Intyre N, Popper K. The critical attitude in medicine: the need for a new ethics. Br Med $\mathrm{J}$ $1983 ; 287: 1919-23$

10. Kroll L, Singleton A, Collier J, Reese Jones I. Learning not to take it seriously: Junior doctor's account of error. Med Educ 2008; 42: 982-90

11. Walton MM. Hierarchies: the Berlin wall of patient safety. Qual Saf in Health Care 2006; 15(4): 22930. [Pub Med PMID: 16885244. Pub Med Central PMCID: PMC 2564017. E pub 2006/08/04. eng ]

12. Leape L, Berwick D, Clancy C, Conway J, Gluck P, Guest J, et al. Transforming Healthcare: a safety imperative. Qua Saf Health Care 2009; 18(6): 424-8 [Pub Med PMID: 19955451. E pub 2009/12/04. eng ]

13. Tevlin R, Doherty E, Traynor O. Improving disclosure and management of medical error-An opportunity to transform the surgeons of tomorrow. The Surgeon $2013 ; 11(6)$ : 338-43. 